\title{
Data-Informed Lifetime Reliability Prediction for Offshore Wind Farms
}

\author{
Alexios Koltsidopoulos Papatzimos ${ }^{1}$ \\ Industrial Doctoral Centre for Offshore Renewable Energy \\ University of Edinburgh \\ Edinburgh, UK \\ A.Koltsidopoulos-Papatzimos@ed.ac.uk
}

\author{
Philipp R. Thies \\ College of Engineering, \\ Mathematics and Physical Sciences \\ University of Exeter \\ Penryn, UK
}

\author{
Jerome Lonchampt \\ Department of Performance, Industrial Risk and Surveillance \\ for Maintenance and Operation \\ EDF R\&D \\ Chatou, France
}

\author{
Antoine Joly, Tariq Dawood \\ ${ }^{1}$ EDF Energy R\&D UK Centre \\ London, UK
}

\begin{abstract}
Offshore wind operation and maintenance (O\&M) costs can reach up to $1 / 3$ of the overall project costs. In order to accelerate the deployment of these clean energy assets, costs need to come down. This requires, a good understanding of the different operations along with a robust planning, maintenance and monitoring strategy. Asset management tools have been developed, which require reliability inputs, able to estimate the lifetime operational expenditure (OPEX) and optimize the maintenance strategies for the assets. The lack of large datasets with offshore wind failure rate data in the literature increases the uncertainty in the estimations made by those tools. This paper aims to compare whether the publicly available data could provide an accurate information of the lifetime reliability predictions of the assets. It initially uses a generic average failure rate, taken from literature to model the wind farm; as most wind farm developers will not have any detailed understanding of the reliability of the asset prior to construction. It then uses a more detailed, turbine-specific model, taking into account reliability data from an operational wind farm. Results show a small overall difference when the model uses the data-informed parameters, by up to $0.4 \%$ in the overall availability. Moreover, it is shown that the use of generic values can create more pessimistic results compared to the data-informed data. The results of the paper are of interest to offshore wind farm developers and operators aiming to improve their lifetime reliability estimations and reduce the O\&M costs of the offshore wind farms.
\end{abstract}

Index Terms-Offshore wind, failure rates, availability, environmental conditions, alarms

\section{INTRODUCTION}

Offshore wind operation and maintenance (O\&M) costs could reach up to $30 \%$ of the total project costs [1]. These costs are relatively high due to accessibility issues and the need of dedicated vessels and personnel for the turbines'

This research was made possible with support through the Industrial Doctorate Centre for Offshore Renewable Energy (IDCORE) funded by the Energy Technology Institute and the RCUK Energy Programme (Grant number: EP/J500847/1) and EDF Energy. repair. Moreover, weather limitations can delay or abort the operations, which can result in longer waiting times for the turbine to be repaired, causing downtime and loss of energy production. During the planning stage of an offshore wind asset, it is crucial to be able to estimate these parameters accurately. Thus wind farm developers are using different asset management tools in order to be able to predict the resources needed, the overall operational expenditure (OPEX) and to optimize their future O\&M strategy. The two key challenges here, which are further discussed below, are the accuracy of the tool to provide a realistic representation of the sequence of the different maintenance tasks and events, as well as the quality and availability of the input data used for the simulation.

\section{A. $O \& M$ tools}

There have been several OPEX estimation and O\&M strategy tools developed over the years for offshore wind farms. These include both commercial and academic solutions. Two studies have compared the findings of the different tools against each other, but neither has been validated through the lifetime of an offshore wind farm [2], [3]. The studies performed are usually simulating the designed lifetime of the assets which is typically 20 years, but they could also be used after the end of the lifetime in order to decide whether or not a lifetime extension would be profitable. In the latter case, more data will be available for the asset and a more accurate estimation can be made. For this study, an in-house asset management tool is used, developed by EDF R\&D, able to simulate any type of offshore operation and tested for both installation and maintenance operations [4].

\section{B. Reliability data}

Onshore wind turbines have a larger pool of operating experience and more published information is readily available, due 
to their longer time of operation. Most of the studies are based on; RELIAWIND database that comprises of 350 turbines [5], Windstats and LWK databases that include 6000 turbines at 11 years of operation [6], [7]. Although these databases have small capacity turbines, most of them under $1 \mathrm{MW}$, they provide interesting reliability statistics that show the differences in failure rates for same capacity turbines between different manufacturers. For example, a difference with a factor up to 2,3 , and 4 has been shown for the blade, pitch and generator subassemblies respectively. Similar results can be seen in [8], where failure rates are grouped with the wind turbine's capacity, where large differences between different capacities are noticed. This makes reliability modelling, especially for new multi-MW turbines, very challenging.

In terms of offshore wind reliability data, there is only one study that has a population of roughly 350 offshore wind turbines, presenting failure rate statistics of up to 9 years of operation [9]. Moreover Dinwoodie et al. [2] have presented failure rate statistics for offshore wind farm from "expert" knowledge. Less detailed studies to the public include the SPARTA database, developed by Offshore Renewable Energy (ORE) Catapult and featuring all the offshore wind farms in the UK [10]. SPARTA provides a list of key performance indicators to the wind farm operators that are part of this initiative and annual reports are published with some generic outputs. By comparing the onshore and offshore studies, a difference of up to 10 times in failure rates can be seen. This emphasises the point on the importance of the accuracy of the reliability parameters.

One approach to better understand how failures are occurring is to closely investigate the effect of environmental conditions on wind turbine failures. Previous studies have explored the effect of wind speed and turbulence intensity on turbine failures, by using wind speed measurements and work order information [9], [11], [12], [13]. Having a good understanding of that information could potentially provide a more accurate estimation of the OPEX costs, as not all wind turbines at the same farm are exposed to the same environmental conditions and not all have the same failure rates [14], [15].

This paper presents a data-informed analysis for the 27 turbine Teesside offshore wind farm. It uses literature findings and turbine specific reliability data generated at Teesside in order to compare the level of analysis that is required by offshore wind farm developers to estimate their OPEX costs and their O\&M strategies prior to the construction of the farm or during the lifetime extension analysis. The paper is structured in 3 parts. Part II presents the methodology for the collection and pre processing of the wind turbine data to create the input parameters, as well as a description of the asset management used and the final input parameters. Part III presents and discusses the different results of the simulations; including a single turbine, a farm with generic data, a farm with data-informed data parameters and a comparison of the different findings. Finally, part IV concludes and proposes future work on this topic.

\section{Methodology}

This study uses reliability data from literature in order to run different scenarios for an operational wind farm in the UK, enhanced with observed data. The site is Teesside offshore wind farm, shown in Fig. 1, comprising of 27 wind turbines, rated at $2.3 \mathrm{MW}$. It further uses an asset management tool to run the different lifetime reliability estimations.

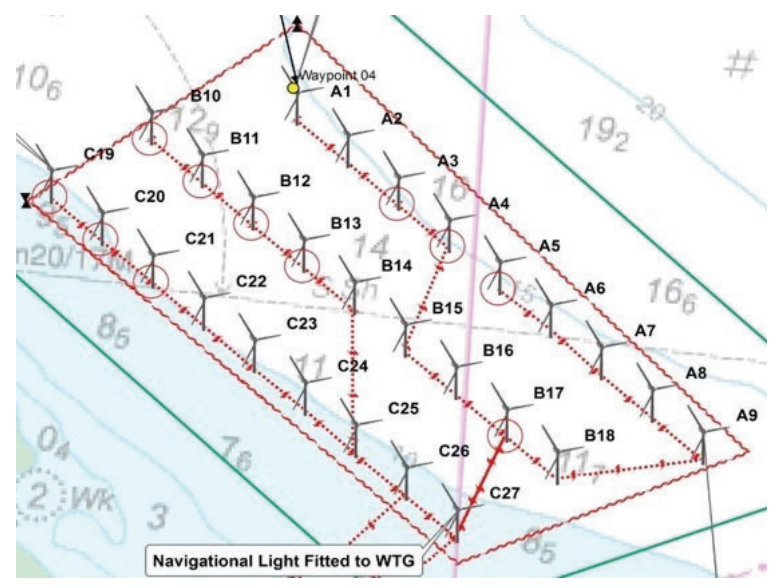

Fig. 1. Teesside Offshore Wind Farm layout [16]

\section{A. Reliability data analysis}

There is very limited research on failure rates for offshore wind farms, with only one study having been presented so far, analysing 300 offshore wind turbines for up to 8 years of operations [9]. It also provides values for a range of subassemblies for minor/ major repairs and major replacement. Manual reset values are missing and are used from Dinwoodie et al. [2]. For the simulations, the ageing of the components is taken into account. There is only one study for onshore wind turbines' ageing characteristics, in terms of power output, which is used as an input for the reliability parameters [17].

This work aims to consider the environmental parameters, thus a data-informed approach is used, by enhancing the literature parameters with site specific ones. This is achieved by analysing 5 years of operation of turbine alarms from the site. Turbine alarms can be a good indicator to detect when a failure has occurred. Historical work order information can also help to create failure rate statistics [4], but do not always indicate the exact time that a failure has occurred; only the time a failure has been detected, repaired or a component has been replaced. An analysis and categorisation of the turbine alarms at Teesside offshore wind farm has been performed. The methodology is summarised in Fig. 2; once the alarms have been retrieved, they are assigned to the different subassemblies, as defined by [9], and then the repetitive alarms are grouped into one instance in order to count it as a single event and then they are assigned to the closest 10minute interval. The work orders are also categorized in subassemblies and converted to a timestamp and both sources are integrated into a relational database, as shown in [14]. The outputs of the model used for this study are shown in Fig. 3. A more 
in depth description and correlation of the alarms with the environmental conditions can be found at Koltsidopoulos et al. [18].

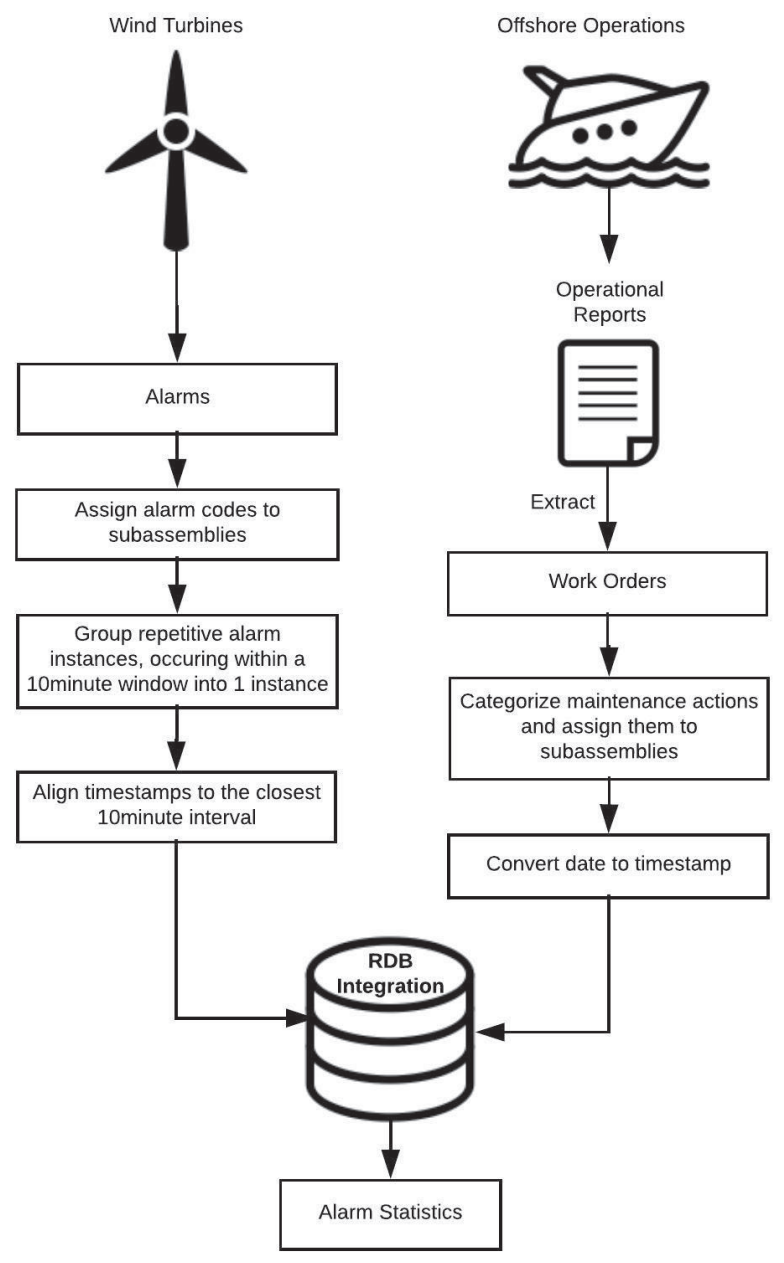

Fig. 2. Teesside alarm data analysis

\section{B. O\&M tool description}

The different scenarios are run using an integrated asset management tool for strategic planning of O\&M activities, developed internally by EDF R\&D. The tool is comprised of 6 modules; weather, reliability, wind turbine, logistic, project and economic, as shown in Fig. 4. The weather and reliability modules are two separate engines generating the weather conditions and the failures that are the intervention instances, which are then simulated by the other four modules. The tool provides as outputs the different associated operational expenditure (OPEX) costs, reliability and availability information of the assets and statistics about the different operations taking place. It runs on a Monte Carlo simulation for all the input parameters and all simulations in this paper have used 10,000 repetitions.
A description of the different modules is shown below.

1) Weather generation: The tool allows different types of weather models to be used; one that uses directly the historical data provided, another one that uses the historical data to create a synthetic weather series using a Neural Networks model and another one that uses historical data to create a synthetic weather series using Markov Switching Autoregressive Model (HS-AR). The parameters used for the weather generation are the wind speed and the wave height of the site. The synthetic time series can create some stochastic weather outputs, which can provide better results when simulating multiple future scenarios. For this study, the HS-AR model is used, as it has previously been validated for the selected site. It uses the homogeneous MS-AR model with Gaussian innovations, embedded within the METIS Matlab simulation tools. A detailed description of the model and its validation can be found at Paterson et al. [19].

2) Reliability: it is used for generating probabilistic or calendar based events. In the first case, the events are generated to simulate unexpected failures of the components and the latter one to simulate preventive maintenance tasks that have been scheduled for a specific period of the year. The generated failures can be designed for as many components as the user requires to every level of detail; from a component up to the system level. The failures are not linked and are governed by the individual input parameters. The tool is able to handle different reliability distribution types; exponential, Weibull, Dirac and a user defined one. Once the failure mode has been triggered, a maintenance task is activated; when the maintenance task is complete the repaired or replaced component can be modelled to be as good as new, as bad as old or to have a new reliability value.

3) Wind Turbine: The wind turbine modules are then linked with the different reliability components triggering the maintenance actions. It is possible to determine the nominal power of the turbine, as well as the capacity factor for every month. These values are used for estimating the total power generation, as well as the economic parameters required.

4) Project management: This module is used to specify the different tasks taking place and are linked to the reliability components. This allows the modelling of all the tasks required for an offshore maintenance operation. For example the transit in and out of the vessel as well as the duration of the task or of individual sub-tasks. It is possible to add restrictions to the tasks, such as weather limitations, as well as technicians' shift time.

5) Logistics: It includes all the resources needed to perform an operation and it is linked to the individual tasks. This includes the available vessels, personnel, equipment and consumables needed for each operation.

6) Economic: All of the operations taking place are linked to a cost, which are then discounted to the present value and aggregated to provide the total OPEX costs.

A more detailed description of the different functionalities of the tool can be found at Lonchampt et al [4]. 


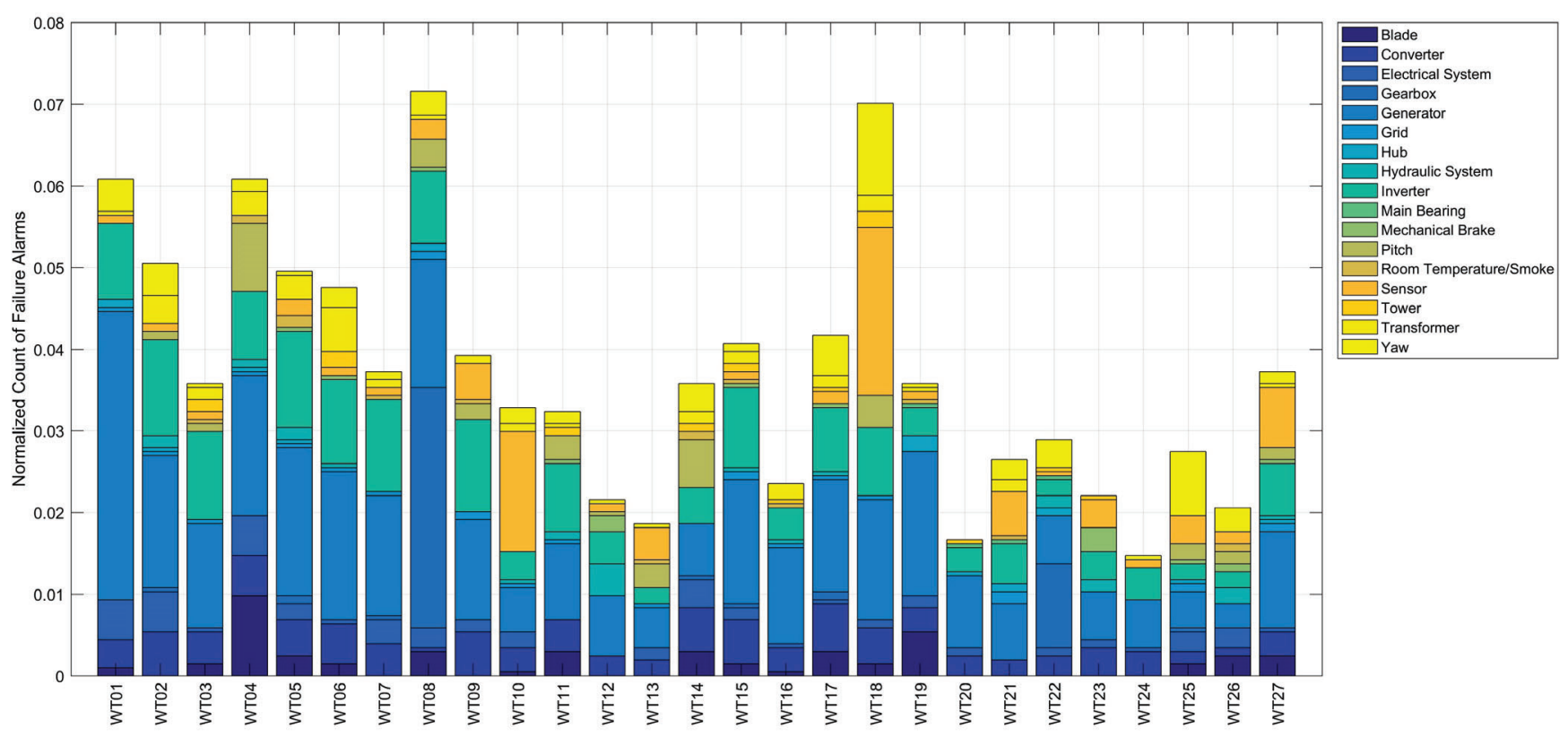

Fig. 3. Normalized failure alarm count, categorized by subassembly for a 5 year period at Teesside offshore wind farm [15]

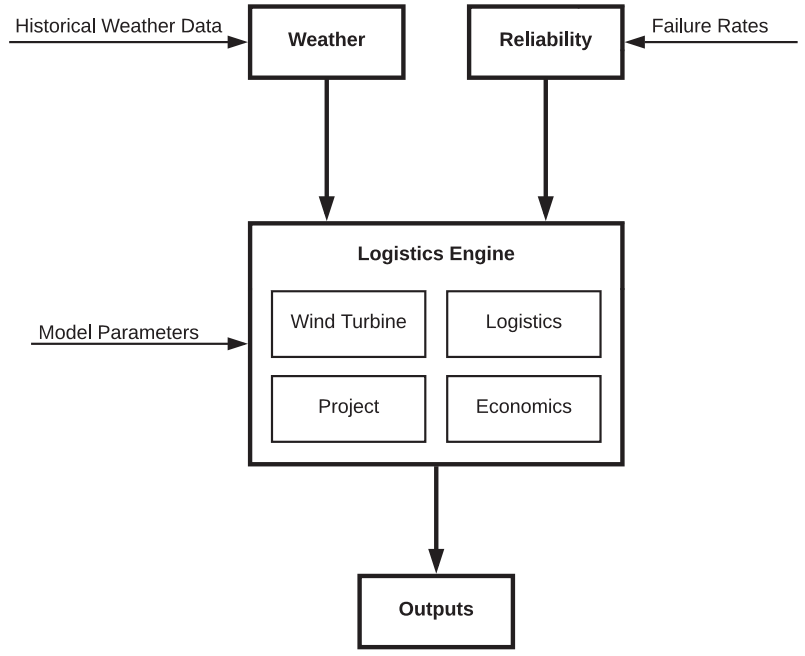

Fig. 4. Overview of the asset management tool

\section{Model Inputs}

Table I shows the generic model input values used for the simulations, taken from [2], [9]. Table II the overall multiplication factors, as derived from Fig. 3 values.

Following is a list of assumptions that are taken under consideration in the model:

- 60 hours of annual maintenance for every turbine, performed during the summer period.

- 10 days of delay for major component replacement, in order to wait for the jack-up vessel to arrive.

- Operations are taking place the whole week (including weekends) from 7:00 until 18:00.

- Operational limits are considered for weather conditions
TABLE I

Generic Model InPuts

\begin{tabular}{|l|c|c|c|c|}
\hline Model Inputs & $\begin{array}{c}\text { Manual } \\
\text { Reset }\end{array}$ & $\begin{array}{c}\text { Minor } \\
\text { Repair }\end{array}$ & $\begin{array}{c}\text { Major } \\
\text { Repair }\end{array}$ & $\begin{array}{c}\text { Major } \\
\text { Replacement }\end{array}$ \\
\hline Failure rate/ turbine/ year & 7.5 & 6.81 & 1.17 & 0.29 \\
\hline Ageing Factor/year & $1.69 \%$ & $1.69 \%$ & $1.69 \%$ & $1.69 \%$ \\
\hline Repair time (h) & 3 & 6.67 & 17.64 & 116.19 \\
\hline Number of technicians & 2 & 3 & 3 & 9 \\
\hline Vessel type & CTV & CTV & CTV & Jack-up \\
\hline
\end{tabular}

TABLE II

OVERALL MULTIPLICATION FACTORS

\begin{tabular}{|c|c||c|c||c|c|}
\hline Turbine & Factor & Turbine & Factor & Turbine & Factor \\
\hline A1 & 1.25 & B10 & 0.97 & C19 & 0.77 \\
\hline A2 & 1.4 & B11 & 0.88 & C20 & 1.01 \\
\hline A3 & 1.01 & B12 & 0.8 & C21 & 0.75 \\
\hline A4 & 1.45 & B13 & 0.6 & C22 & 0.97 \\
\hline A5 & 1.27 & B14 & 0.95 & C23 & 0.72 \\
\hline A6 & 1.3 & B15 & 1.02 & C24 & 0.71 \\
\hline A7 & 1.19 & B16 & 0.92 & C25 & 0.74 \\
\hline A8 & 1.34 & B17 & 0.99 & C26 & 0.88 \\
\hline A9 & 1.02 & B18 & 1.12 & C27 & 0.96 \\
\hline
\end{tabular}

above $1.5 \mathrm{~m}$ of significant wave height and $12 \mathrm{~m} / \mathrm{s}$ of wind speed.

- The failure rates were modelled using a Weibull distribution for the different cases, as shown in Eq. 1; where $\mathrm{t}$ is the time when the failure occurs, $\lambda$ the scale factor and $\beta$ the shape factor. In the case where ageing is taken under consideration $\beta=1.07$ and the component is considered "as bad as old" after the maintenance has taken place. In 
the case where ageing is not taken under consideration $\beta=1.0$ and the component is considered "as good as new". The scale factor was then converted to a daily value by dividing the failure rate in Table I with the number of hours in a year; 8760 .

$$
R(t)=e^{-(\lambda * t)^{\beta}}
$$

- There is always a CTV available on site.

- Turbine is shut down when an operation takes place.

- Turbine is immediately shut down only when a major repair is required, assuming that the turbine cannot operate and is shut down until the technicians arrive and fix the fault. In the case of minor repairs, the turbine does not need to be shut down and when a major replacement is needed, it is assumed that it takes place before the catastrophic failure of the component and it has been identified predicted well in advance; thus, a shut down is not required.

The different scenarios that have been considered in the paper are the following:

- One turbine (with and without ageing)

- Teesside offshore wind farm with average reliability values to all the turbines (with and without ageing)

- Teesside offshore wind farm with data-informed reliability parameters (with and without ageing)

In order to compare the results, two different metrics are used; time-based availability (TBA) [20] and production-based availability (PBA) [21]. TBA is the fraction of the time that the turbine is available (i.e. it is not shut down for any maintenance or due to a failure) over the total operational time of the asset, as shown in Eq. 2. PBA is the fraction of the actual energy produced by the asset over the potentially energy expected (i.e. including the energy lost when the turbine was shut down), shown in Eq. 3. These are calculated in the tool, by providing the average monthly capacity factors at Teesside offshore wind farm, which are undisclosed due to confidentiality reasons.

$$
\begin{gathered}
\text { TBA }=\frac{\text { TimeAvailable }}{\text { TotalTimeConsidered }} \\
P B A=\frac{\text { EnergyActuallyProduced }}{\text { EnergyPotentiallyExpected }}
\end{gathered}
$$

\section{RESUlTS AND DISCUSSION}

The results are presented below for the different scenarios.

\section{A. Single Turbine}

Fig. 5 shows the time based and production based availability values for a single turbine over a 20 year period. The turbine considered is turbine A1, with regards to its distance from the port and the generic model inputs are used for the different failure modes. As expected, PBA values are lower than the TBA ones. The asset management tool is accurate

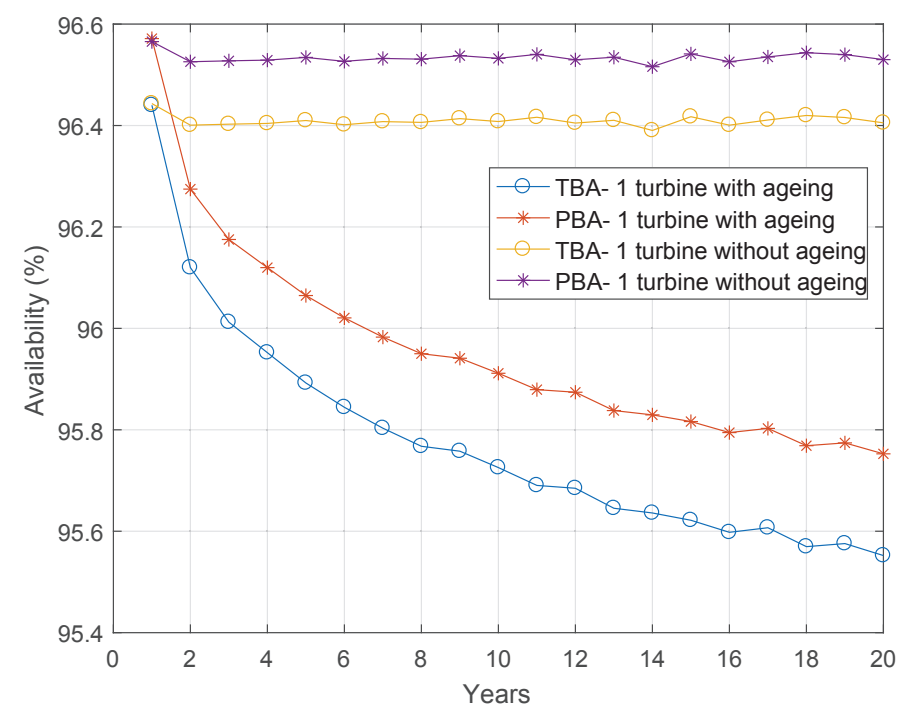

Fig. 5. Time and production based availability for 1 turbine, with and without ageing for 20 years of lifetime.

enough and able to pick even those small differences in availability and reliability calculations. The failure rate generation results are shown in Fig. 6 for the different types of failure considered with and without taking into account the ageing factor. The failure rates using the ageing factor, are increasing on an average of $1.69 \%$, in order to simulate the degradation. For the cases without ageing, the failure rate values are fluctuating around the average value. As there are no studies indicating the failure rate over the lifetime of the assets, this is considered a sufficient assumption. Spinato et al. [7] have presented an attempt to model the failures of subassemblies through time, but with only 5 years of operational data. The study showed that generator and electrical systems tend to follow the bathtub curve, whereas gearboxes tend to have a linear increase of failures over time. This type of modelling is not used for this study, as it varies between literature finding and turbine manufacturer and it is not clear yet what the most representative failure distribution curve is. Instead, an increased failure rate over time is considered through the ageing parameter since the only available study shows a power degradation of the turbine over its lifetime.

\section{B. Wind farm with generic values}

Fig. 7 shows the TBA for the simulated case of the Teesside wind farm, using the generic input values. The simulation with the ageing parameters is shown at the lower part of the figure and without the ageing parameters is shown at the top. All the individual turbines follow the same pattern and the small differences between are caused due to the different distance from the port which could result in longer or shorter downtime periods. By comparing the wind farm results with the ones from the individual turbine model, turbine $\mathrm{A} 1$ has a $0.5 \%$ lower overall availability when it was by itself compared to when it was simulated on the farm. This is due to the resource unavailability, as the technicians and/ or the CTV might be on 


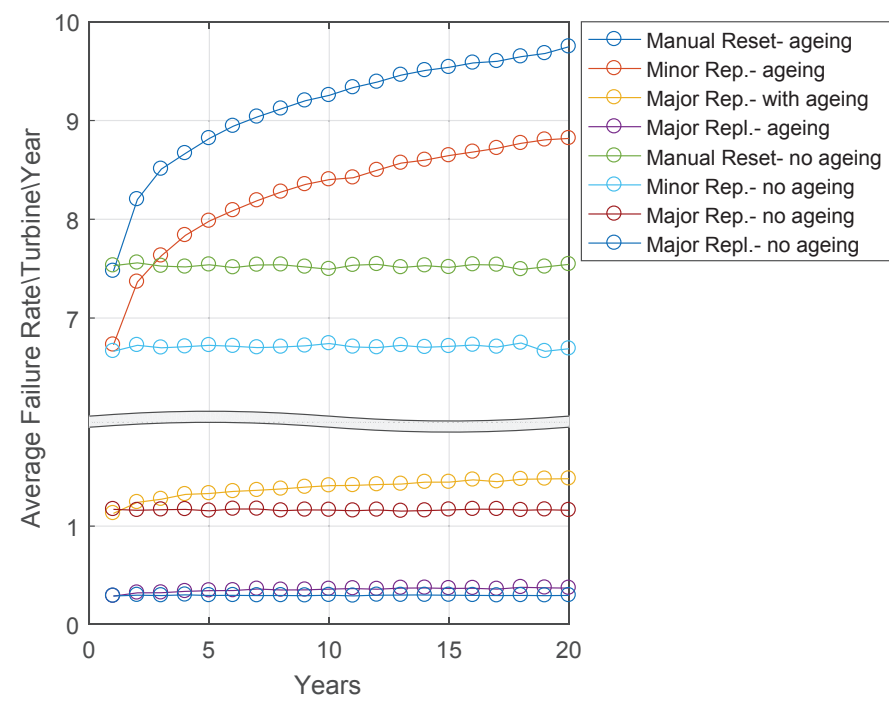

Fig. 6. Failure rate evolution over time for 20 years for 1 turbine (including manual reset, minor repair, major repair and major replacement with and without ageing)

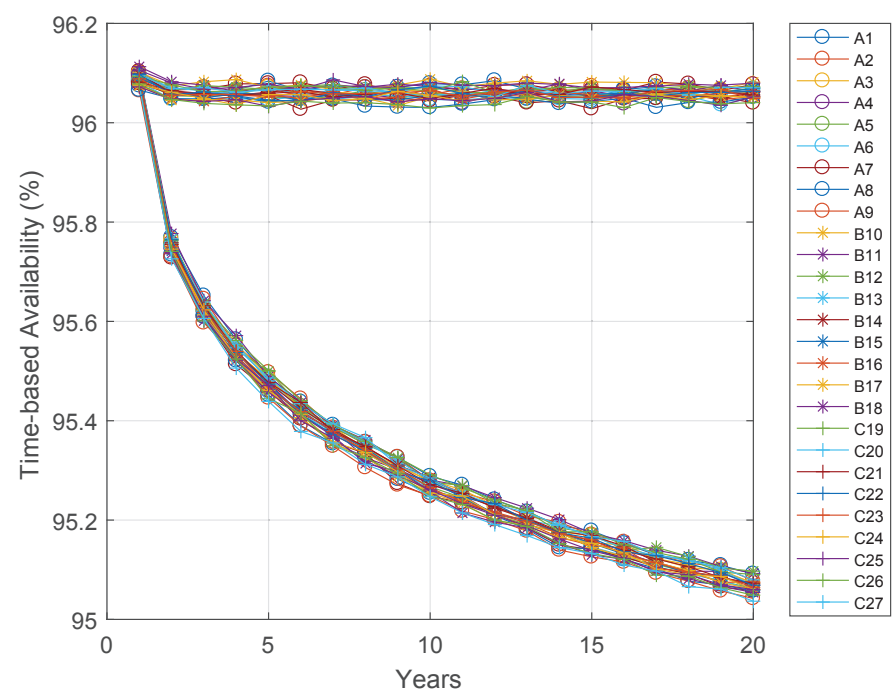

Fig. 7. Time based availability for 27 turbines over 20 years for the generic wind farm case. The top 27 lines correspond to the cases without ageing and the bottom ones with ageing.

another turbine. The overall availability difference could be translated to around $22 \mathrm{GWh}$ difference for the 20 years of operation, which could be around $£ 6.5 \mathrm{~m}$. of OPEX costs.

\section{Wind farm with data-informed parameters}

Fig. 8(a) shows the TBA for the simulated case of the Teesside wind farm, taking under consideration the datainformed parameters from Table II and the ageing factor. Fig. 8(b) has the same input parameters, but without ageing. In both cases the turbines perform according to the different input parameters and the multiplication factor used. There were no added significant delays from any unexpected events and all the turbines followed the same trend. There are a few overlaps in the TBA values for example between turbines A1 and A5 as well as turbines C20, A3, C19 and B15. This is possibly due to any failure or weather downtime or any vessel delays.

\section{Comparison}

For the different cases in the previous section, the average time and production based availability values are shown in Fig. 9 Moreover, the difference between the highest and lowest availability values are shown in Table III.

TABLE III

TURBINE AVAILABILITY COMPARISON

\begin{tabular}{|l|c|c|c|}
\hline Cases & $\begin{array}{c}\text { Highest } \\
\text { Availability }\end{array}$ & $\begin{array}{c}\text { Lowest } \\
\text { Availability }\end{array}$ & Difference \\
\hline $\begin{array}{l}\text { Generic failure rates- no } \\
\text { ageing }\end{array}$ & C27 & B11 & $0.04 \%$ \\
\hline $\begin{array}{l}\text { Generic failure rates- with } \\
\text { ageing }\end{array}$ & C27 & B11 & $0.05 \%$ \\
\hline $\begin{array}{l}\text { Turbine specific failure } \\
\text { rates- no ageing }\end{array}$ & A4 & B13 & $2.48 \%$ \\
\hline $\begin{array}{l}\text { Turbine specific failure } \\
\text { rates- with ageing }\end{array}$ & A4 & B13 & $3.16 \%$ \\
\hline
\end{tabular}

It is interesting to see that in the case where the datainformed parameters were taken into consideration, the TBA and PBA values are higher. This could be due to the fact that as the failures are defined by different failure rate values, they will no happen close to them in time happening at the same time, and thus the resources can be managed more effectively. It shows that in the case where generic values are used for OPEX modelling, the overall values are more pessimistic and an average $0.22 \%$ increase in production and in revenue can be simulated with the data-informed parameters. This difference could also be lower or higher, depending on the weather parameters that are chosen each time to run the simulation, as they are stochastic. Similarly the TBA values for the datainformed case were higher on average by $0.25 \%$ compared to the generic ones. The overall availability difference could be translated to around 10GWh difference for the 20 years of operation, which could be around $£ 3 \mathrm{~m}$. of OPEX costs.

There is very limited literature in the availability of offshore wind farm. An early study [22] indicated that Round 1 UK offshore wind farms experienced a TBA of $80.2 \%$. The study was performed before Teesside was built. A more recent study from ORE Catapult [23], including all the offshore wind farms in the UK indicated that the 50th percentile of the wind turbines have an average PBA of $96.31 \%$, with the 90th percentile being at $98.57 \%$ and the 10th percentile being at $90.28 \%$. This includes a range of wind turbines and wind farm sizes and distances from the port. Comparing the results of this study with the ORE Catapult's report, Teesside's PBA values seem reasonable, as the wind farm is close to the shore and an intervention can be made easily, as an effect the overall PBA values are very close to the 50th percentile values form the report.

This comparison indicates that the currently publicly available data can be used by offshore wind farm developers as an estimate, as they represent the average cases and it is a 


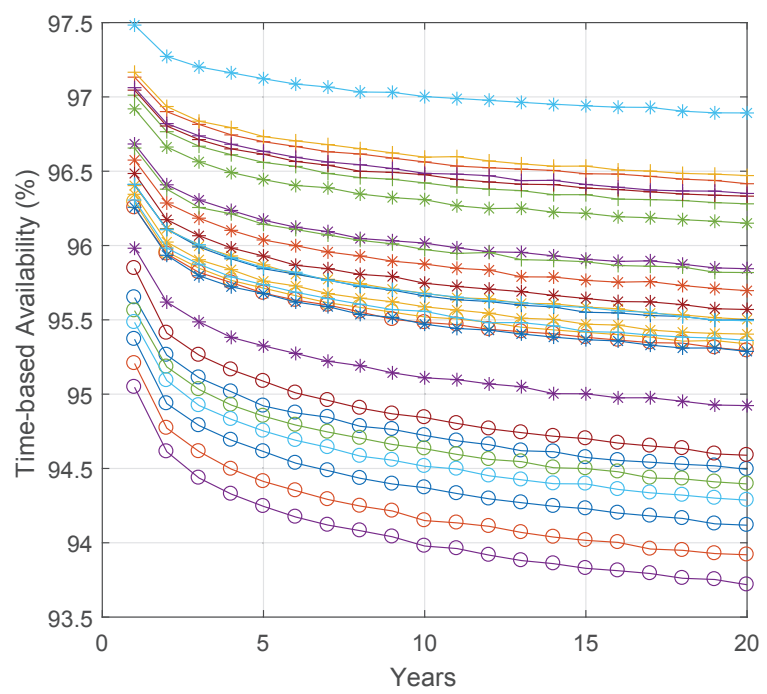

(a) With ageing

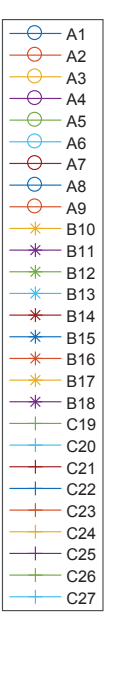

Fig. 8. Time based availability for 27 turbines with data-informed parameters for 20 years

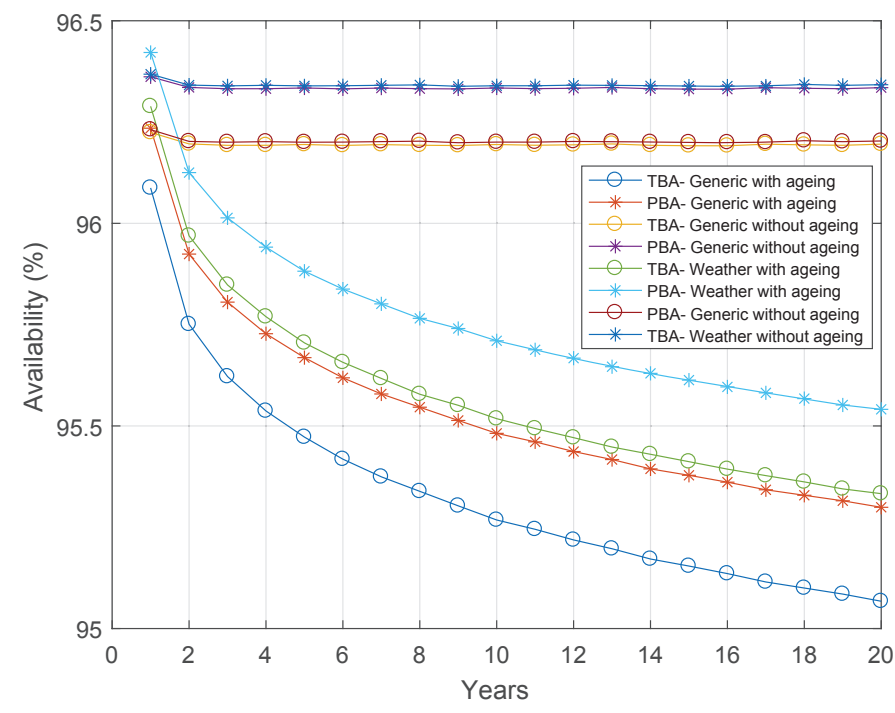

Fig. 9. Comparison of average time based and production based availability values for 27 turbines with and without ageing over 20 years of operation.

good starting point. Once the operators have a more detailed understanding of the asset, they can refine those data with their own parameters in order to make more realistic predictions.

\section{Conclusion}

This paper presented a comparison between publicly available data for lifetime availability estimation, compared to datainformed ones. The study used an asset management tool in order to generate the different simulations. The data-informed parameters have been created by analysing the failure alarms of an operational wind farm.

Key findings from this paper show that:

- When generic failure rates are used for the all the turbines, the availability values are governed by the turbine

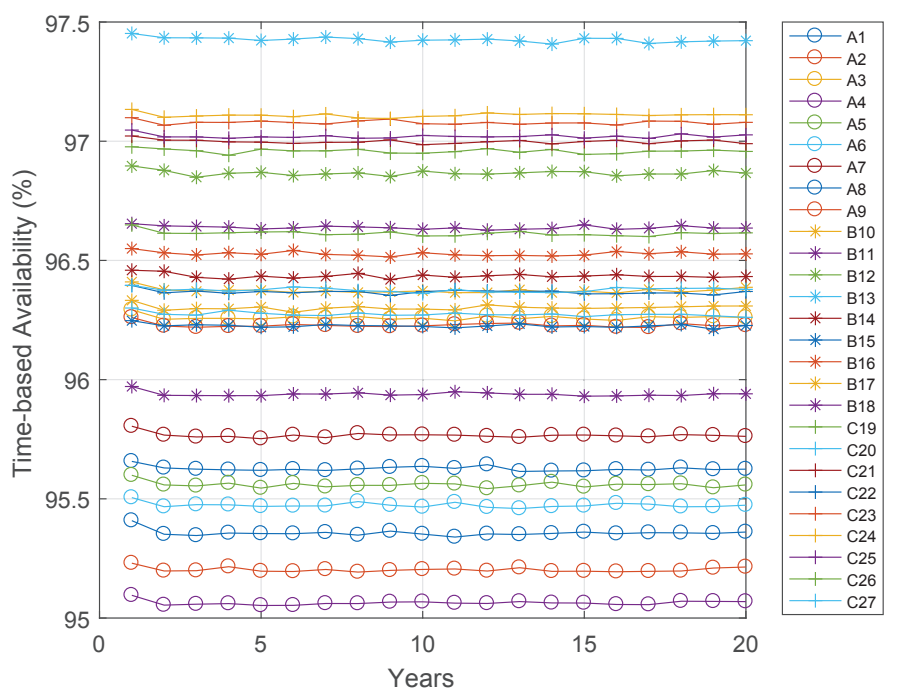

(b) Without ageing distance from the port.

- There is a small difference when taking the data-informed data into account in the overall availability of up to $0.4 \%$.

- Generic failure rate data generate more pessimistic results compared to data-informed ones, as failures do not occur at the same time.

- The overall PBA values estimated in this study are in agreement with operational findings.

The results show that the failure rates and reliability estimates available literature can be a reasonable starting point for wind farm operators to estimate the expected O\&M activities and farm availability. However, they reliability information should subsequently be refined for more accurate predictions. Future work could focus on better understanding and modelling the failure modes and their ageing in higher detail. At the moment more detailed inputs are needed in order to understand and model the physics of failure.

\section{ACKNOWLEDGMENT}

The authors would like to thank EDF Renewables UK for providing access to the data.

\section{REFERENCES}

[1] A. Ioannou A, A. Angus, and F. Brennan, "A lifecycle techno-economic model of offshore wind energy for different entry and exit instances," Applied Energy, vol. 221, pp. 406-424, 2018.

[2] I. Dinwoodie, Iain, O.E.V. Endrerud, M. Hofmann, R. Martin, and I.B. Sperstad, "Reference Cases for Verification of Operation and Maintenance Simulation Models for Offshore Wind Farms," Wind Engineering, vol. 39, no. 1, pp. 1-14. doi:10.1260/0309-524X.39.1.1.

[3] I.B. Sperstad, M. Stålhane, I. Dinwoodie, O.E.V. Endrerud, R. Martin, and E. Warner, "Testing the robustness of optimal access vessel fleet selection for operation and maintenance of offshore wind farms," Ocean Engineering, vol. 145, pp.334-343, 2017.

[4] J. Lonchampt, A. Joly, T. Dawood, and A. Koltsidopoulos Papatzimos, "An integrated asset management model for offshore wind turbine," in Proc. 29th Int Ocean and Polar Engineering Conference (ISOPE), Honolulu, Hawaii, Jun. 2019. 
[5] GH, "Reliability-focused research on optimizing Wind Energy system design, operation and maintenance: Tools, proof of concepts, guidelines \& methodologies for a new generation," ReliaWind, 2007.

[6] P.J. Tavner, J. Xiang, and F. Spinato, "Reliability Analysis for Wind Turbine," Wind Energy, vol. 10, pp. 1-8, 2007.

[7] F. Spinato, P.J. Tavner, G.J.W. van Bussel, and E. Koutoulakos, "Reliability of wind turbine subassemblies," IET Renewable Power Generation, vol. 3, no. 4, pp. 387-401, 2009.

[8] J. Ribrant, and M. Bertling, M., 2007, "Survey of Failures in Wind Power Systems With Focus on Swedish Wind Power Plants During 1997-2005," IEEE Trans. Energy Convers., vol. 22, no. 1, 2007.

[9] J. Carroll, A. McDonald, and D. McMillan, "Failure rate, repair time and unscheduled O\&M cost analysis of 310 offshore wind turbines," Wind Energy, vol. 19, pp. 1107-1119, 2016.

[10] N. Simpson, "SPARTA project - System Performance, Availability and Reliability Trend Analysis," in Proc. All-Energy Exhibition \& Conference, Aberdeen, UK, May 2014.

[11] M. Reder, N.Y. Yurusen, and J.J. Melero "Data-driven learning framework for associating weather conditions and wind turbine failures," Reliability Engineering \& System Safety 2018; 169: 554-569.

[12] P.J. Tavner, C. Edwards, A. Brinkman, and F. Spinato, "Influence of Wind Speed on Wind Turbine Reliability," Wind Engineering, vol. 30, no. 1, pp. 55-72, 2006.

[13] V. Kourkoulis, J. Carroll, and W. Leithead, "Effect of site conditions on offshore wind turbine failures," in Proc. International Conference on Renewable Power Generation (RPG 2015), Beijing, China, Oct. 2015, pp. 837-842.

[14] A. Koltsidopoulos Papatzimos, T. Dawood, and P.R. Thies, "An Integrated Data Management Approach for Offshore Wind Turbine Failure Root Cause Analysis," in Proc. International Conference on Offshore Mechanics and Arctic Engineering, vol. 3B :V03BT02A012. doi:10.1115/OMAE2017-62279.

[15] A. Koltsidopoulos Papatzimos, T. Dawood, and P.R. Thies, "Data-Driven Operational Reliability Assessment for Offshore Wind Farms," Reliability Engineering \& System Safety (Under Review).

[16] “Teesside Offshore Wind Farm-Construction Information - PD Ports," PD Ports, 2013.

[17] I. Staffell, and R. Green, "How does wind farm performance decline with age?," Renewable Energy, vol. 66, pp. 775-786, 2014.

[18] A. Koltsidopoulos Papatzimos, T. Dawood, and P.R. Thies, "Offshore Wind Turbine Fault Alarm Prediction," Proc IMechE Part O: J Risk and Reliability (Under Review).

[19] J. Paterson, P.R. Thies, R. Sueur, J. Lonchampt, and F. D'Amico, "Assessing marine operations with a Markov-switching autoregressive metocean model," Proc IMechE Part M: J Engineering for the Maritime Environment (Under Review).

[20] IEC, "Wind turbines - Part 26-1: Time-based availability for wind turbine generating systems", IEC TS 61400-26-1:2011, Published 14 Nov 2011.

[21] IEC, "Wind turbines - Part 26-2: Production-based availability for wind turbine generating systems", IEC TS 61400-26-2:2014, Published 4 June 2014.

[22] Y. Feng, P. J. Tavner, and H. Long, "Early experiences of UK round 1 offshore wind farms," Proceedings of the Institution of Civil EngineersEnergy vol. 163, no. 4, pp. 167-181, 2010.

[23] ORE Catapult, "System Performance, Availability and Reliability Trend Analysis - SPARTA: 2017/18 Portfolio Review,” 2018. 